\title{
Risk factors for poor adherence to inhaled corticosteroid therapy in patients with moderate to severe asthma
}

\author{
Katsunori Masaki, ${ }^{1,2}$ Jun Miyata, ${ }^{1,3}$ Takashi Kamatani, ${ }^{1,4,5}$ Takae Tanosaki, ${ }^{1,2}$ Takao Mochimaru, ${ }^{1,2}$ Hiroki Kabata, ${ }^{1,2}$ \\ Yusuke Suzuki, ${ }^{6}$ Koichiro Asano, ${ }^{7}$ Tomoko Betsuyaku, ${ }^{1}$ Koichi Fukunaga ${ }^{1,2}$
}

\begin{abstract}
Background: Poor adherence to inhaled corticosteroid (ICS) therapy is a common reason for worsened asthma control.

Objective: We investigated the characteristics of patients with moderate to severe asthma who showed poor adherence to therapy, to identify the barriers for optimal ICS therapy in a real-world observational cohort.

Methods: We enrolled patients aged $\geq 20$ years presenting with moderate to severe asthma who were enrolled at 18 hospitals in Japan. According to the Global Initiative for Asthma 2018 steps 3-5, the patients were considered as moderate to severe asthmatic. At inclusion, clinical information was obtained using a self-completed questionnaire. Poor adherence was defined as skipping the ICS therapy for more than once a week or inability to recognize the necessity of daily ICS therapy. Adherence Starts with Knowledge 20 (ASK-20) questionnaire was used to evaluate the cause of therapy incompliance.

Results: Of the total 85 participants, 19 (22\%) showed poor adherence. The median age at diagnosis in the poor adherence group was 10.0 years (interquartile range [IQR], 3.0-50.0), and that in the good adherence group was 41.0 years (18.5-51.5; $\mathrm{P}=0.050$ ). The scores for the ASK-20 items related to the "resistance to taking too much medicine" and "compliance with the number of dosing" demonstrated statistically significant differences between patients diagnosed with asthma during their childhood and others.
\end{abstract}

Conclusion: Age at diagnosis is an independent risk factor to predict poor ICS adherence among adults with moderate to severe asthma.

Key words: Adherence, Age at onset, Asthma, Difficult-to-control asthma, Inhaled corticosteroids, Severe asthma, Risk factor

From:

${ }^{1}$ Division of Pulmonary Medicine, Department of Medicine,

Keio University School of Medicine, Tokyo, Japan

${ }^{2}$ Keio Allergy Center, Keio University Hospital, Tokyo, Japan

${ }^{3}$ Division of Infectious Diseases and Respiratory Medicine, Department of Internal Medicine, National Defense Medical College, Saitama, Japan

${ }^{4}$ Department of Biological Sciences, Graduate School of Science, University of Tokyo, Tokyo, Japan

5 Department of Medical Science Mathematics, Tokyo Medical and Dental University, Tokyo, Japan

${ }^{6}$ Department of Respiratory Medicine, Kitasato Institute Hospital, Tokyo, Japan

Division of Pulmonary Medicine, Department of Medicine, Tokai University, School of Medicine, Kanagawa, Japan

\section{Corresponding author:}

Katsunori Masaki

Division of Pulmonary Medicine, Department of Medicine,

Keio University School of Medicine,

35 Shinanomachi, Shinjuku-ku, Tokyo 160-8582, Japan

E-mail: masaki@keiomed.com

\section{Introduction}

Continuous treatment with inhaled corticosteroid (ICS) plays an important role in controlling chronic airway inflammation and improving the quality of life in asthmatics. ${ }^{1,2,3} \mathrm{Al}$ though alternative drugs, including leukotriene receptor antagonists, may be effective in real-world clinical settings, ${ }^{4}$ ICS is the primary agent with strong therapeutic potential for asthma control. Thus, poor adherence to ICS therapy causes poor disease control in patients with difficult-to-control asthma. ${ }^{5,6}$ 
Differences in adherence between the prospective studies and real-world use may lead to different therapeutic effects of anti-asthma drugs. ${ }^{4}$ Nearly half of the asthmatics who were prescribed oral steroids were non-adherent to ICS therapy. ${ }^{6,7} \mathrm{Re}-$ cently, efforts to improve the adherence to inhaled medicine have been taken in clinical settings, and inhaler reminders offered an effective strategy for better adherence to a steroid inhaler as primary care. ${ }^{8}$ Gamble J et al reported that poor adherence in difficult-to control asthma could be improved when identified and targeted. ${ }^{9}$ Therefore, it provides a therapeutic opportunity to identify the characteristics of poor-adherent asthmatics.

Many researchers focused on the age of asthmatics to report poorer adherence of older adults with asthma. ${ }^{10-14}$ Conversely, another study reported the association between increased age and better adherence in the Japanese population. ${ }^{15}$ Meanwhile, a meta-analysis of observational studies on the determinants of asthma inhaler adherence among adults did not report any association between age and adherence to ICS. ${ }^{16}$ There is still controversy about factors influencing ICS adherence. Identification of patient-specific barrier for adherence is essential to improve the adherence to ICS for optimal therapeutic strategy. The Adherence Starts with Knowledge 20 (ASK-20) questionnaire was developed to evaluate these barriers. ${ }^{17,18,19}$ The ASK-20 consisted of 20 clinically actionable questionnaires that assessed medication adherence. The ASK20 can be used to identify specific barriers to adherence among patients with chronic diseases. Furthermore, ASK-20 scores of asthmatic patients demonstrated a negative correlation between treatment adherence and barriers, ${ }^{20,21}$ suggestive of the usefulness of ASK-20 as a questionnaire for patient characterization.

In this study, we aimed to investigate clinical characteristics of poor-adherent moderate to severe asthmatic patients and to identify the barriers to ICS adherence using the ASK-20 questionnaire.

\section{Methods}

\section{Study Design}

This study was retrospective, non-interventional, and multicentered. We enrolled patients with age $\geq 20$ years who presented with moderate to severe asthma at 18 hospitals in Japan. ${ }^{22,23}$ Moderate to severe asthma was defined based on the criteria by the Global Initiative for Asthma (GINA) guideline 2018. ${ }^{3}$ Asthma requiring step 3-5 treatments (including ICS and/or long-acting B-agonists or muscarinic antagonists, and anti-IgE drugs) to achieve optimal disease control was considered as moderate to severe. The patients with malignant tumors or diffuse lung disease were excluded from the study. However, the patients with chronic obstructive pulmonary disease (i.e., asthma and chronic obstructive pulmonary disease overlap: ACO) were not excluded because the prevalence of ACO was around 11-60\% among individuals with asthma and information about this population was important to address the aim of this study. ${ }^{24}$

\section{Collection of Clinical Information}

At inclusion, clinical information was obtained using a self-completed questionnaire. The status of asthma control was determined using Japanese versions of the asthma control test (ACT) questionnaire. A previous report demonstrated the validity of the Japanese version of the ACT used with individuals with mild to severe asthma symptoms. ${ }^{25}$ Data of laboratory findings and medications were obtained from the medical records.

Pulmonary function during stable asthma status was measured using a CHESTAC-9800 spirometer (Chest, Tokyo, Japan), which accommodates the criteria of the American Thoracic Society. The predicted values of forced expiratory volume in $1 \mathrm{~s}$ for Japanese population were calculated using the lambda-mu-sigma method proposed by the Japanese Respiratory Society. ${ }^{26}$ The fraction of exhaled nitric oxide was measured using a Sievers Nitric Oxide Analyzer (GE Healthcare Japan, Tokyo, Japan).

\section{Evaluation of Adherence}

The patients were asked to answer the question in the self-reporting questionnaire, "How often do you forget inhalation of asthma controller?" They selected one answer from the following five options: \#1) Never / Rare, \#2) Sometimes (once or twice a week), \#3) Often, \#4) Always, \#5) Not been prescribed. Poor adherence was defined as skipping ICS inhalation for more than once a week (answers \#2-\#4) or inability to recognize the daily necessity of ICS therapy (answer \#5). Adherence status was also determined using the ASK-20 questionnaire. ${ }^{18}$ The items of ASK-20 are noted in Table $\mathbf{1 .}$

Table 1. The scores of ASK-20 ${ }^{\dagger}$ items in whole study population

\begin{tabular}{|c|c|c|}
\hline$\# 1$. & I just forget to take my medicine some of the time. & $2.5 \pm 1.4$ \\
\hline$\# 2$. & I run out of my medicine because I don't get refills on time. & $1.3 \pm 0.6$ \\
\hline$\# 3$. & My use of alcohol gets in the way of taking my medicines. & $1.3 \pm 0.6$ \\
\hline$\# 4$. & I worry about how medicine will affect my sexual health. & $1.5 \pm 0.9$ \\
\hline \#5. & I sometimes forget things that are important to me. & $1.8 \pm 1.0$ \\
\hline \#6. & I have felt sad, down, or blue during the past month. & $2.4 \pm 1.4$ \\
\hline$\# 7$. & I feel confident that each one of my medicines will help me. & $1.7 \pm 0.7$ \\
\hline \#8. & I know if I am reaching my health goals. & $2.4 \pm 1.0$ \\
\hline \#9. & I have someone whom I can call with questions about my medicines. & $2.5 \pm 1.2$ \\
\hline
\end{tabular}


Table 1. (Continued)

\begin{tabular}{|c|c|}
\hline \#10. I understand my doctor's/nurse's instructions about the medicines I take. & $1.6 \pm 0.6$ \\
\hline \#11. My doctor/nurse and I work together to make decisions. & $1.8 \pm 0.9$ \\
\hline \#12. I am able to read and understand pill bottle labels. & $1.7 \pm 0.5$ \\
\hline \#13. Taking medicines more than once a day is inconvenient. & $2.5 \pm 1.3$ \\
\hline \#14. I have to take too many medicines a day. & $2.5 \pm 1.4$ \\
\hline \#15. It is hard for me to swallow the pills I have to take. & $1.8 \pm 1.0$ \\
\hline \#16. Taken a medicine more or less often than prescribed? & $2.1 \pm 1.4$ \\
\hline \#17. Skipped or stopped taking a medicine because you didn't think it was working? & $1.1 \pm 0.4$ \\
\hline \#18. Skipped or stopped taking medicine because it made you feel bad? & $1.1 \pm 0.4$ \\
\hline \#19. Skipped, stopped, not refilled, or taken less medicine because of the cost? & $1.0 \pm 0.1$ \\
\hline \#20. Not had medicine with you when it was time to take it? & $1.5 \pm 0.8$ \\
\hline ASK-20 total score & $36.1 \pm 8.0$ \\
\hline ASK-20 total barrier count & $2.7 \pm 2.0$ \\
\hline
\end{tabular}

All values are described as mean \pm standard deviation

ASK-20 Adherence Starts with Knowledge 20

${ }^{\dagger}$ We used the Japanese version of ASK-20 in this study.

\section{Statistical Analysis}

Data were expressed as mean \pm standard deviation, median (interquartile range [IQR]), or proportion (\%). The t-test or Mann-Whitney U test, and $\chi^{2}$ test were used to analyse the continuous and categorical variables, respectively. A multivariate logistic regression analysis was performed to calculate the odds ratio and the $95 \%$ confidence interval, following adjustment for the baseline characteristics (i.e., age at diagnosis, sex, and smoking status). A statistically significant difference was defined as a two-tailed p-value $<0.05$. All statistical analyses were performed using IBM SPSS statistical software package for Mac OS, version 24.0 (IBM Corporation, Armonk, NY, USA).

\section{Ethical Approval}

The study protocol was approved by the institutional review board of each participating institution (approval number: 2009-9-5). The protocol was implemented in compliance with the Declaration of Helsinki. All participants provided written informed consent and patient anonymity was preserved using the methods approved by the Ethics Committee.

\section{Results}

We analysed 85 patients with moderate to severe asthma who met the inclusion criteria. Baseline characteristics of the study participants are shown in Table 2. Among the participants, $45 \%$ were male and the mean age was 58.9 years. Thirteen patients (15\%) suffered a near-fatal asthma attack and three-tenth of the population were admitted to date. All patients were prescribed ICS and needed multiple antiasthma drugs. The median and IQR of ACT score was 21.0 and 16.0-23.0, respectively, and four-tenth of patients exhibited ACT scores below 20, indicative of poor asthma control.
Table 2. Clinical characteristics of patients in study population

\begin{tabular}{|lc|}
\hline \multicolumn{1}{|c}{ Characteristics } & $\mathbf{N}=\mathbf{8 5}$ \\
\hline Demographics & \\
\hline GINA step 3,4,5 (N) & $16,42,27$ \\
\hline Males (\%) & 45 \\
\hline Age (mean \pm SD) & $58.9 \pm 14.4$ \\
\hline Age at diagnosis (median [IQR]) & $39.0(7.5-50.5)$ \\
\hline Diagnosed during childhood (<16 years) (\%) & 31 \\
\hline BMI (kg/m ${ }^{2}$ ) (median [IQR]) & $23.6 \pm 4.4$ \\
\hline History of smoking $\left.{ }^{\dagger} \%\right)$ & 40 \\
\hline Brinkman Index (median [IQR]) & $0(0 \pm 212)$ \\
\hline Comorbidities & 18 \\
\hline Aspirin intolerance (\%) & 31 \\
\hline Atopic dermatitis (\%) & 61 \\
\hline Allergic rhinitis (\%) & $21.0(16.0-23.0)$ \\
\hline GERD (\%) & 40 \\
\hline Exacerbation and symptom & 22 \\
\hline History of near-fatal attack (\%) & 70 \\
\hline Usage of short-term OCS (\%) & 15 \\
\hline Unscheduled visit (\%) & \\
\hline Admission (\%) & \\
\hline ACT score (median [IQR]) & \\
\hline ACT score < 20 (\%) & \\
\hline
\end{tabular}


Table 2. (Continued)

\begin{tabular}{|c|c|}
\hline Characteristics & $\mathbf{N}=\mathbf{8 5}$ \\
\hline \multicolumn{2}{|l|}{ Biomarkers } \\
\hline Eosinophil (\%) (median [IQR]) & $5.3(2.2-8.3)$ \\
\hline Eosinophil $(/ \mu \mathrm{L})($ median $[\mathrm{IQR}])$ & $291(132-570)$ \\
\hline Total IgE (IU/mL) (median [IQR]) & $294(138-705)$ \\
\hline FeNO (ppb) (median [IQR]) & $32.4(13.9-58.7)$ \\
\hline \multicolumn{2}{|l|}{ Pulmonary functions } \\
\hline $\mathrm{FEV}_{1} / \mathrm{FVC}(\%)($ mean $\pm \mathrm{SD})$ & $65.7 \pm 17.0$ \\
\hline $\mathrm{FEV}_{1}(\% \text { predicted })^{\ddagger}($ mean $\pm \mathrm{SD})$ & $77.6 \pm 21.1$ \\
\hline $\begin{array}{l}\mathrm{FEV}_{1}\left(\% \text { predicted) after SABA inhalation }{ }^{*} \text { (mean }\right. \\
\pm \mathrm{SD})\end{array}$ & $84.9 \pm 24.6$ \\
\hline \multicolumn{2}{|l|}{ Medication } \\
\hline ICS $(\mu \mathrm{g} / \text { day })^{\varsigma}($ median $[\mathrm{IQR}])$ & $800(400-1000)$ \\
\hline OCS, \% & 29 \\
\hline LABA, \% & 74 \\
\hline LAMA, \% & 27 \\
\hline LTRA, \% & 73 \\
\hline Theophylline, \% & 47 \\
\hline Omalizumab, \% & 14 \\
\hline
\end{tabular}

ICS, inhaled corticosteroids; GINA, Global Initiative for Asthma; SD, standard deviation; IQR, interquartile range; BMI, body mass index; GERD, gastroesophageal reflux disease; OCS, oral corticosteroid; ACT, asthma control test; IgE, immunoglobulin E; FeNO, fractional exhaled nitric oxide; $\mathrm{FEV}_{1}$, forced expiratory volume in 1 second; FVC, forced vital capacity; SABA, short-acting beta-agonist; LABA, long-acting beta-agonist; LAMA, long-acting muscarinic antagonist; LTRA, leukotriene receptor antagonist; ASK-20 Adherence Starts with Knowledge 20

${ }^{\dagger}$ Brinkman Index $\geq 400$

* The predicted values were calculated on the reference equation proposed by the Japanese Respiratory Society.

${ }^{\S}$ Dose of ICS was shown as fluticasone propionate equivalent.
Table 3. ICS adherence in study population

\begin{tabular}{lc}
$\begin{array}{l}\text { Question. How often do you forget inhalation of asthma } \\
\text { controller? }\end{array}$ & N (\%) \\
\hline Good adherence (answer; \#1 never/rare) & $66(78 \%)$ \\
Poor adherence (sum of all below; \#2-\#5) & $19(22 \%)$ \\
\hline Answer; \#2 sometimes (once or twice a week) & $14(16 \%)$ \\
Answer; \#3 often & $3(4 \%)$ \\
Answer; \#4 always & $0(0 \%)$ \\
Answer; \#5 not been prescribed (really prescribed) & $2(2 \%)$ \\
\hline
\end{tabular}

ICS, inhaled corticosteroids

Table 3 shows ICS adherence in the study population. Sixty-six patients (78\%) answered "never / rare" about the frequency of forgetting ICS inhalation and others (19 patients, 22\%) were defined as poor-adherent patients. The number of patients who forgot inhalation more than three times a week was only three (4\%), and two patients did not understand that they need daily inhalation despite ICS prescription. The mean ASK-20 total score and total barrier count in the study population were 36.1 and 2.7, respectively (Table $\mathbf{1}$ ).

Table 4 shows the relationship between ICS adherence and clinical features. The median age at diagnosis differed between patients with poor ICS adherence (10.0 years; IQR, 3.0-50.0) and those with good ICS adherence (41.0 years; IQR, 18.551.5) $(\mathrm{P}=0.047)$. Furthermore, ASK-20 total score was associated with ICS adherence $(\mathrm{P}=0.048)$. Patients with poor ICS adherence presented higher total scores of ASK-20 than those of patients with good ICS adherence, although the difference did not reach statistical significance $(P=0.063$; Table 5). There were no statistically significant differences in smoking history, laboratory data, pulmonary function, the score related to the symptoms and exacerbation, and treatment intensity. Multivariate analysis showed consistent results (odds ratio: 0.974, 95\% confidence interval: $0.948-0.999, \mathrm{P}=0.042$ ) after adjusting for other variables such as sex, the status of disease control (ACT score), and number of cigarettes smoked per day (Table 6).

Table 4. Clinical characteristics of patients with good or poor ICS adherence

\begin{tabular}{|c|c|c|c|}
\hline \multirow{2}{*}{ Characteristics } & \multicolumn{2}{|c|}{ ICS adherence } & \multirow{2}{*}{ P-value } \\
\hline & Good $(N=66)$ & Poor $(\mathrm{N}=19)$ & \\
\hline \multicolumn{4}{|l|}{ Demographics } \\
\hline GINA step 3, 4, $5(\mathrm{~N})$ & $10,33,23$ & $6,9,4$ & - \\
\hline Males (\%) & 44 & 47 & $0.791^{*}$ \\
\hline Age (mean \pm SD) & $60.5 \pm 12.8$ & $53.5 \pm 18.5$ & $0.125^{* *}$ \\
\hline Age at diagnosis (median [IQR]) & $41.0(18.5-51.5)$ & $10.0(3.0-50.0)$ & $0.047^{* * *}$ \\
\hline Diagnosed during childhood (<16 years) (\%) & 23 & 58 & $<0.003^{*}$ \\
\hline BMI $\left(\mathrm{kg} / \mathrm{m}^{2}\right)($ median $[\mathrm{IQR}])$ & $23.5 \pm 4.1$ & $24.0 \pm 5.1$ & $0.692^{* *}$ \\
\hline History of smoking ${ }^{\dagger}(\%)$ & 42 & 32 & $0.404^{*}$ \\
\hline Brinkman Index (median [IQR]) & $0(0-231)$ & $0(0-160)$ & $0.441^{* * *}$ \\
\hline
\end{tabular}


Table 4. (Continued)

\begin{tabular}{|c|c|c|c|}
\hline \multirow{2}{*}{ Characteristics } & \multicolumn{2}{|c|}{ ICS adherence } & \multirow{2}{*}{ P-value } \\
\hline & Good $(N=66)$ & Poor $(\mathrm{N}=19)$ & \\
\hline \multicolumn{4}{|l|}{ Exacerbation and symptom } \\
\hline History of near-fatal attack (\%) & 16 & 12 & $0.677^{\star}$ \\
\hline Usage of short-term OCS (\%) & 72 & 63 & $0.470^{*}$ \\
\hline Unscheduled visit (\%) & 61 & 58 & $0.832^{*}$ \\
\hline Admission (\%) & 29 & 32 & $0.811^{\star}$ \\
\hline ACT score (median [IQR]) & $21.0(16.0-23.0)$ & $22.0(19.0-24.0)$ & $0.559^{* * *}$ \\
\hline ACT score < $20(\%)$ & 43 & 32 & $0.370^{*}$ \\
\hline \multicolumn{4}{|l|}{ Biomarkers } \\
\hline Eosinophil (\%) (median [IQR]) & $4.9(2.0-9.8)$ & $5.4(3.8-7.7)$ & $0.690^{* * *}$ \\
\hline Eosinophil $(/ \mu \mathrm{L})($ median $[\mathrm{IQR}])$ & $269(117-671)$ & $302(198-369)$ & $0.741^{* * *}$ \\
\hline Total IgE (IU/mL) (median [IQR]) & $281(139-638)$ & $400(137-1000)$ & $0.732^{* * *}$ \\
\hline FeNO (ppb) (median [IQR]) & $29.3(13.4-55.3)$ & $38.0(24.7-101.8)$ & $0.343^{* * *}$ \\
\hline \multicolumn{4}{|l|}{ ASK-20 } \\
\hline ASK-20 total score (mean \pm SD) & $35.2 \pm 7.8$ & $39.2 \pm 7.8$ & $0.048^{* *}$ \\
\hline ASK-20 TBC (mean \pm SD) & $2.5 \pm 2.0$ & $3.4 \pm 2.1$ & $0.082^{* *}$ \\
\hline
\end{tabular}

ICS, inhaled corticosteroids; GINA, Global Initiative for Asthma; SD, standard deviation; IQR, interquartile range; BMI, body mass index; ACT, asthma control test; IgE, immunoglobulin E; FeNO, fractional exhaled nitric oxide; ASK-20 Adherence Starts with Knowledge 20

${ }^{*} \chi^{2}$ test

$* *$ t-test

$* * *$ Mann-Whitney U test

$\dagger$ Brinkman Index $\geq 400$

* We used the Japanese version of ASK-20 in this study.

Table 5. The scores of ASK-20 items in patients with good or poor ICS adherence

\begin{tabular}{|c|c|c|c|c|}
\hline & \multirow{2}{*}{ 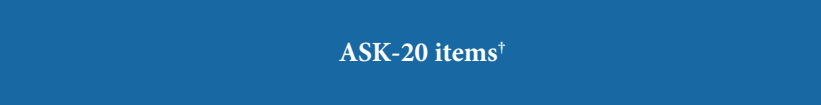 } & \multicolumn{2}{|c|}{ ICS adherence } & \multirow{2}{*}{ P-value } \\
\hline & & $\operatorname{Good}(\mathbf{N}=66)$ & Poor $(N=19)$ & \\
\hline \#1. & I just forget to take my medicine some of the time. & $2.0(1.0-4.0)$ & $4.0(2.0-4.0)$ & 0.077 \\
\hline$\# 2$. & I run out of my medicine because I don't get refills on time. & $1.0(1.0-1.25)$ & $1.0(1.0-2.0)$ & 0.273 \\
\hline \#3. & My use of alcohol gets in the way of taking my medicines. & $1.0(1.0-1.25)$ & $1.0(1.0-2.0)$ & 0.476 \\
\hline$\# 4$. & I worry about how medicine will affect my sexual health. & $1.0(1.0-2.0)$ & $1.0(1.0-3.0)$ & 0.074 \\
\hline \#5. & I sometimes forget things that are important to me. & $1.0(1.0-2.0)$ & $2.0(1.0-3.0)$ & 0.025 \\
\hline \#6. & I have felt sad, down, or blue during the past month. & $2.0(1.0-4.0)$ & $2.0(1.0-4.0)$ & 0.567 \\
\hline \#7. & I feel confident that each one of my medicines will help me. & $2.0(1.0-2.0)$ & $2.0(1.0-2.0)$ & 0.352 \\
\hline$\# 8$. & I know if I am reaching my health goals. & $2.0(1.75-3.0)$ & $2.0(2.0-3.0)$ & 0.809 \\
\hline \#9. & I have someone whom I can call with questions about my medicines. & $2.0(2.0-3.0)$ & $2.0(2.0-4.0)$ & 0.310 \\
\hline$\# 10$. & I understand my doctor's/nurse's instructions about the medicines I take. & $2.0(1.0-2.0)$ & $2.0(1.0-2.0)$ & 0.416 \\
\hline$\# 11$. & My doctor/nurse and I work together to make decisions. & $2.0(1.0-2.0)$ & $2.0(1.0-2.0)$ & 0.332 \\
\hline$\# 12$. & I am able to read and understand pill bottle labels. & $2.0(1.0-2.0)$ & $2.0(2.0-2.0)$ & 0.413 \\
\hline \#13. & Taking medicines more than once a day is inconvenient. & $2.0(1.0-3.0)$ & $3.0(2.0-4.0)$ & 0.251 \\
\hline$\# 14$. & I have to take too many medicines a day. & $2.0(1.0-4.0)$ & $2.0(1.0-4.0)$ & 0.939 \\
\hline$\# 15$. & It is hard for me to swallow the pills I have to take. & $2.0(1.0-2.0)$ & $1.0(1.0-2.0)$ & 0.279 \\
\hline
\end{tabular}


Table 5. (Continued)

\begin{tabular}{|c|c|c|c|}
\hline \multirow{2}{*}{ ASK-20 items ${ }^{\dagger}$} & \multicolumn{2}{|c|}{ ICS adherence } & \multirow{2}{*}{ P-value } \\
\hline & Good $(N=66)$ & Poor $(\mathbf{N}=19)$ & \\
\hline \#16. Taken a medicine more or less often than prescribed? & $1.0(1.0-3.0)$ & $3.0(1.0-4.0)$ & 0.063 \\
\hline \#17. Skipped or stopped taking a medicine because you didn't think it was working? & $1.0(1.0-1.0)$ & $1.0(1.0-1.0)$ & 0.658 \\
\hline \#18. Skipped or stopped taking medicine because it made you feel bad? & $1.0(1.0-1.0)$ & $1.0(1.0-1.0)$ & 0.710 \\
\hline \#19. Skipped, stopped, not refilled, or taken less medicine because of the cost? & $1.0(1.0-1.0)$ & $1.0(1.0-1.0)$ & 0.592 \\
\hline \#20. Not had medicine with you when it was time to take it? & $1.0(1.0-1.0)$ & $1.0(1.0-1.0)$ & 0.087 \\
\hline ASK-20 total score & $34.5(29.8-41.0)$ & $38.0(33.0-45.0)$ & 0.063 \\
\hline ASK-20 TBC & $2.0(1.0-4.0)$ & $3.0(1.0-5.0)$ & 0.076 \\
\hline
\end{tabular}

All values are described as mean \pm standard deviation

${ }^{\dagger}$ We used the Japanese version of ASK-20 in this study.

ASK-20, Adherence Starts with Knowledge 20; ICS, inhaled corticosteroid

Table 6. Multivariate logistic regression analyses of baseline characteristics representing poor adherence indicators.

\begin{tabular}{|lcc|}
\hline & Odds ratio $(95 \%$ CI $)$ & P-value \\
\hline Age at diagnosis & $0.974(0.948-0.999)$ & 0.042 \\
\hline $\begin{array}{l}\text { Male sex } \\
\begin{array}{l}\text { Number of cigarettes smoked per } \\
\text { day }\end{array}\end{array}$ & $0.763(0.222-2.624)$ & 0.673 \\
\hline ACT score & $1.000(0.938-1.065)$ & 0.993 \\
\hline
\end{tabular}

CI, confidence interval; ACT, asthma control test

The prevalence of barrier determined by each ASK-20 item such as "\#14. I have to take too many medicines a day." ( $42.3 \%$ vs $18.6 \%, P=0.032$ ), and "\#16. Taken a medicine more or less often than prescribed?” (53.8\% vs $25.4 \%, \mathrm{P}=0.011$ ) was different between the childhood-diagnosed ( $<16$ years) patients and others ( $\geq 16$ years). We set age threshold as 16 years between childhood and adulthood because patients under or above the age of 16 years are usually consulted at the paediatric department or internal medicine department, respectively, in Japan. No statistically significant differences were demonstrated between the two groups for the scores of items regarding cognitive disturbances (ASK-20 \#5) and depression (ASK-20 \#6).

\section{Discussion}

The present study suggested the relationship between age at diagnosis of asthma and adherence to ICS therapy among patients with moderate to severe asthma, which provides important indications.

First, younger age at diagnosis of asthma was a significant and independent risk factor for poor ICS adherence. In our study, we analysed the data of moderate to severe asthma patients with unstable disease control (IQR of ACT score was 16.0-23.0) who mostly did their best to improve their symptoms. Nevertheless, more than one-fifth of patients (22\%) were poor-adherent although they had continuous or continual symptoms; their symptoms could be alleviated if their adherence improved. Poor adherence to treatment, a common problem among asthmatic children, should be considered in all children with uncontrolled asthma. ${ }^{27,28,29}$ Recently diagnosed patients with asthma receive an explanation about the importance of ICS in the optimal treatment of asthma. However, patients diagnosed with asthma during childhood may show habitual poor adherence because a similar emphasis on ICS treatment is generally absent. Moreover, a decrease in drug adherence is observed in children with chronic diseases. For example, in childhood-onset type 1 diabetes, poor drug adherence tends to persist through the period from middle adolescence to adulthood. ${ }^{30,31}$ Similarly, established poor adherence in patients with childhood-onset asthma might be carried over to adulthood. In addition, there is a possibility that the era of diagnosis may affect patients' adherence. The importance of adherence in asthma was first mentioned in the GINA guideline in 2011, ${ }^{3}$ indicating that those diagnosed with asthma before these guidelines were published may not have been educated for the importance of good compliance to treatment.

Second, we revealed that the two items "loss of strictness to taking routine medication routinely (ASK-20 \#16)" and "misunderstanding of the importance of key drug (ASK-20 \#14)" resulted in poor adherence in patients with younger age at the diagnosis. More than half of the patients diagnosed during childhood did not recognize the importance of compliance with drug dosage, which inhibited the development of good ICS adherence. Additionally, patients with childhood-onset asthma might experience declined adherence to ICS in association with decreased opportunity to contact former doctors, pharmacists, and nurses. Physician's explanation to patients' parents about the importance of ICS might not improve its understanding in adolescent subjects.

There are a few limitations of the present study. First, it was impossible to accurately analyse the causal relationship because of the retrospective study design. Second, we checked ICS adherence of the participants based on their self-reported questionnaires and we could not evaluate the appropriate inhaler techniques. ${ }^{32}$ Third, the sample number was too small to conclude any definite association. In addition, patients with 
mild asthma were not included in this study because these individuals generally demonstrate better asthma control status than those with moderate or severe asthma. Finally, we could not strictly distinguish patients with ACO from those with pure asthma. However, prospective analysis, possibly with periodical confirmation of ICS consumption, might induce better compliance to ICS therapy in the study population, suggesting that retrospective analysis might be superior to evaluate real-world situation for treatment adherence.

\section{Conclusion}

In conclusion, age at diagnosis is an independent risk factor for poor adherence to ICS therapy in adults with moderate to severe asthma. Clinicians should assess age at diagnosis, course of treatment, and adherence before diagnosing a patient as severe asthmatic because of its relationship with treatment adherence. Educational approach to improve therapy compliance, especially during a transition period from childhood to adulthood, might be useful for successful management of severe asthma.

\section{Conflict of Interest}

K. Asano received consultancy from Teijin Pharma Co. Ltd., expert testimony from Chugai Pharmaceutical Co. Ltd., and lecture fees from Astellas Pharma, Kyorin Pharma, Novartis Pharma, Boelinger-Ingelheim, MSD, T. Betsuyaku received a grant from GlaxoSmithKline. K. Fukunaga received lecture fees from Astrazeneca, Boelinger-Ingelheim.

\section{Funding}

This study was supported in part by a Grant-in-Aid for Scientific Research (C) (25461504) from the Japan Society for the Promotion of Science (K. Asano), a Research Grant on Allergic Disease and Immunology from the Japan Agency for Medical Research and Development (K. Asano), and a Grantin-aid from Glaxo-Smith-Kline, PLC (T. Betsuyaku).

\section{Author Contributions}

We thank Chiyomi Uemura, Rie Baba, Kengo Ohtsuka, Masako Matsusaka, Soichiro Ueda, Fumio Sakamaki, Yoshitaka Oyamada, Takashi Inoue, Ichiro Nakachi, Tsuyoshi Oguma, Koichi Sayama, Hidefumi Koh, Morio Nakamura, Akira Umeda, and all members of the Keio severe asthma research program for their assistance.

\section{References}

1. Ernst P, Spitzer WO, Suissa S, Cockcroft D, Habbick B, Horwitz RI, et al. Risk of fatal and near-fatal asthma in relation to inhaled corticosteroid use. JAMA. 1992;268:3462-4.

2. Murphy AC, Proeschal A, Brightling CE, Wardlaw AJ, Pavord I, Bradding P, et al. The relationship between clinical outcomes and medication adherence in difficult-to-control asthma. Thorax. 2012;67:751-3.

3. Global initiative for asthma report [Internet]. Fontana: Global Initiative for Asthma; c2018 [cited 2018 Jul 21]. Global strategy for asthma management and prevention. Updated 2018; Available from http://ginasthma.org.

4. Chen W, Schatz M, Liang Z, Li Q, Sadikova E, Zhang Z, et al. Controller therapy in Asians and whites with persistent Asthma. Asian Pac J Allergy Immunol. 2019;37(2):73-86.
5. Williams LK, Peterson EL, Wells K, Ahmedani BK, Kumar R, Burchard EG, et al. Quantifying the proportion of severe asthma exacerbations attributable to inhaled corticosteroid nonadherence. J Allergy Clin Immunol. 2011;128:1185-91.

6. Williams LK, Pladevall M, Xi H, Peterson EL, Joseph C, Lafata JE, et al. Relationship between adherence to inhaled corticosteroids and poor outcomes among adults with asthma. J Allergy Clin Immunol. 2004;114: 1288-93.

7. Gamble J, Stevenson M, McClean E, Heaney LG. The prevalence of nonadherence in difficult asthma. Am J Respir Crit Care Med. 2009;180: 817-22.

8. Foster JM, Usherwood T, Smith L, Sawyer SM, Xuan W, Rand CS, et al. Inhaler reminders improve adherence with controller treatment in primary care patients with asthma. J Allergy Clin Immunol. 2014;134:1260-8.

9. Gamble J, Stevenson M, Heaney LG. A study of a multi-level intervention to improve non-adherence in difficult to control asthma. Respir Med. 2011;105:1308-15

10. Apter AJ, Wan F, Reisine S. Bender B, Rand C, Bogen DK, et al. The association of health literacy with adherence and outcomes in moderate -severe asthma. J Allergy Clin Immunol. 2013;132:321-7.

11. Bozek A, Jarzab J. Adherence to asthma therapy in elderly patients. J Asthma. 2010;47:162-5.

12. Federman AD, Wolf MS, Sofianou A, Martynenko M, O'Connor R, Halm EA, et al. Self-management behaviors in older adults with asthma: associations with health literacy. J Am Geriatr Soc. 2014;62:872-9.

13. Apter AJ, Boston RC, George M, Norfleet AL, Tenhave T, Coyne JC, et al. Modifiable barriers to adherence to inhaled steroids among adults with asthma: it's not just black and white. J Allergy Clin Immunol. 2003;111: 1219-26.

14. Apter AJ, Reisine ST, Affleck G, Barrows E, ZuWallack RL. Adherence with twice-daily dosing of inhaled steroids. Socioeconomic and health-belief differences. Am J Respir Crit Care Med. 1998;157:1810-7.

15. Takemura M, Kobayashi M, Kimura K, Mitsui K, Masui H, Koyama M, et al. Repeated instruction on inhalation technique improves adherence to the therapeutic regimen in asthma. J Asthma. 2010;47:202-8.

16. Dima AL, Hernandez G, Cunillera O, Ferrer M, deBruin M; ASTRO-LAB group. Asthma inhaler adherence determinants in adults: systematic review of observational data. Eur Respir J. 2015;45:994-1018.

17. Hahn SR, Park J, Skinner EP, Yu-Isenberg KS, Weaver MB, Crawford B, et al. Development of the ASK-20 adherence barrier survey. Curr Med Res Opin. 2008;24:2127-38.

18. Atsuta R, To Y, Sakamoto S, Mukai I, Kobayashi A, Kinoshita A, et al. Assessing usability of the "Adherence Starts with Knowledge 20" (ASK-20) questionnaire for Japanese adults with bronchial asthma receiving inhaled corticosteroids long term. Allergol Int. 2017;66:411-7.

19. Matza LS, Yu-Isenberg KS, Coyne KS, Park J, Wakefield J, Skinner EP, et al. Further testing of the reliability and validity of the ASK-20 adherence barrier questionnaire in a medical center outpatient population. Curr Med Res Opin. 2008;24:3197-206.

20. Park J, Jackson J, Skinner E, Ranghell K, Saiers J, Cherney B. Impactofanadherence intervention program on medication adherence barriers, asthma control, and productivity/daily activities in patients with asthma. J Asthma. 2010;47:1072-7.

21. Sasaki J, Kawayama T, Yoshida M, Takahashi K, Fujii K, Machida K, Kinoshita T, et al. Adherence barriers to inhaled medicines in Japanese older patients with asthma evaluated using the "Adherence Starts with Knowledge 20" (ASK-20) questionnaire. J Asthma. 2019;56:632-41.

22. Matsusaka M, Kabata H, Fukunaga K, Suzuki Y, Masaki K, Mochimaru T, et al. Phenotype of asthma related with high serum periostin levels. Allergol Int. 2015;64:175-80.

23. Masaki K, Fukunaga K, Matsusaka M, Kabata H, Tanosaki T, Mochimaru $\mathrm{T}$, et al. Characteristics of severe asthma with fungal sensitization. Ann Allergy Asthma Immunol. 2017;119:253-7.

24. Uchida A, Sakaue K, Inoue H. Epidemiology of asthma-chronic obstructive pulmonary disease overlap (ACO). Allergol Int. 2018;67(2):165-71.

25. Hasegawa T, Koya T, Sakagami T, Kagamu H, Kawakami H, Hara K, et al. Efficacy of using the Japanese version of the asthma control test for determing the level of asthma control in clinical settings. Allergol Int. 2012;61:609-17.

26. Kubota M, Kobayashi H, Quanjer PH, Omori H, Tatsumi K, Kanazawa M, et al. Reference values for spirometry, including vital capacity, in Japanese adults calculated with the LMS method and compared with previous values. Respir Investig. 2014;52:242-50. 


\section{APJAI}

27. Ramratnam SK, Bacharier LB, Guilbert TW. Severe asthma in children. J Allergy Clin Immunol Pract. 2017;5:889-98.

28. Bracken M, Fleming L, Hall P, Van Stiphout N, Bossley C, Biggart E, et al. The importance of nurse-led home visits in the assessment of children with problematic asthma. Arch Dis Child. 2009;94:780-4.

29. Chan AHY, Stewart AW, Foster JM, Mitchell EA, Camargo CA Jr, Harrison J. Factors associated with medication adherence in school-aged children with asthma. ERJ Open Res. 2016;2:00087-2015.

30. Wiebe DJ, Berg CA, Korbel C, Palmer DL, Beveridge RM, Upchurch R, et al. Children's appraisals of maternal involvement in coping with diabetes: enhancing our understanding of adherence, metabolic control, and quality of life across adolescence. J Pediatr Psychol. 2005;30:167-78.
31. Kovacs M, Goldston D, Obrosky DS, Iyengar S. Prevalence and predictors of pervasive noncompliance with medical treatment among youths with insulin-dependent diabetes mellitus. J Am Acad Child Adolesc Psychiatry. 1992;31:1112-9.

32. Pothirat C, Chaiwong W, Limsukon A, Phetsuk N, Chetsadaphan N, Choomuang W, et al. Real-world observational study of the evaluation of inhaler techniques in asthma patients. Asian Pac J Allergy Immunol [Preprint]. 2019 [cited 2020 Mar 10] Available from: http://apjai-journal. org/wp-content/uploads/2019/02/AP-210618-0348.pdf 